\title{
Practices Used by Excellent Department Chairs to Enhance the Growth and Development of Faculty
}

\section{Myra Wilhite \& Anita Leininger}

University of Nebraska-Lincoln

A college or university is only as good as its faculty. As Dressel (1981) writes, "The major work of the university is done by the faculty...and coordinated by administrative sources" (p. 27). Indeed, the faculty together with academic department heads in particular, are key to the successful operation of the university. Given the importance of faculty within the institution, their development and continued productivity becomes critical to the vitality of the university. Faculty development programs present institutions of higher education with opportunities to keep faculty current and to build excellence from within. One promising and economical approach to faculty development builds on the current institutional structure by working through first-line managers in higher education, the academic department chairperson. If, as Dressel suggests, most faculty find that their immediate concerns and involvement in the institution are through their departments, then department heads are in a particularly pivotal position to encourage, support, and recognize growth and development activities of their faculty.

The purpose of this study was to identify behaviors and practices used by academic department chairpersons to enhance the professional growth and development of faculty and to describe the conditions which affect

From To Improve the Academy: Resources for Student, Faculty, and Institutional Development, Vol. 7. Edited by J. Kurfiss, L. Hilsen, S. Kahn, M.D. Sorcinelli, and R. Tiberius. POD/New Forums Press, 1988. 
these behaviors. While department heads acknowledge their responsibility for the enhancement of faculty growth and development, they are sometimes poorly prepared to assume this role (Boice, 1985). Most department chairs are promoted to these positions through the academic ranks with little or no leadership training and without a clear understanding of the skills of managing and facilitating the growth of faculty and staff. Knight and Holen contend that this inexperience "...intensifies the need for information concerning the behavior characteristics of department chairpersons who are perceived to be effective" $(1985$, p. 685).

Most investigators, while acknowledging the development of faculty as a legitimate function of the department head (Bragg, 1980; McLaughlin, Montgomery \& Malpass, 1975; Smart \& Elton, 1976) and even a preferred role (McLaughlin, et al., 1975), have limited their discussions to the identification of roles rather than an examination of specific behaviors. Tucker (1984) and Bennett (1983), for example, described the roles, functions, and responsibilities of department chairpersons based on data collected from over 1,000 administrators since 1980. Other investigators have studied the complexity of the role (Bragg, 1980; McLaughlin, et al., 1981; Smart \& Elton, 1976) with emphasis on the technical functions (e.g., budgeting, scheduling) rather than on the human resource functions (e.g., leadership, personnel and program planning, problemsolving). Wheeler, Creswell, Mitchell \& Seagren (1986) described the roles and activities used by outstanding department heads to assist faculty growth and development. The researchers concluded that the chairpersons have little or no training for the roles identified.

These studies suggest that while numerous roles and functions of the academic department chairperson have been identified, there is more written about the technical functions than the human resource functions. In addition, studies identifying specific behaviors used by department heads are limited. What is needed is more research on the "practical dimensions" of the position (Tucker, 1984) with major emphasis on the identification of "behavior characteristics" of effective department chairs (Knight \& Holen, 1985). This study attempts to meet that need by identifying specific behaviors and practices used by effective department chairs to assist faculty professionally.

\section{Research Questions}

Given that the development of faculty is seen as a legitimate function of the department head (Bragg, 1980; McLaughlin, Montgomery, \& Malpass, 1975), that department heads are poorly prepared to assume this 
role (Knight \& Holen, 1985), and that past studies have limited their discussions to the identification of roles, functions, and responsibilities, (Wheeler, Creswell, Mitchell, \& Seagren, 1986; Bragg, 1981), this study focuses on behaviors used by academic department chairpersons to enhance the professional growth and development of faculty and describes conditions which affect these behaviors. The study also identifies sources of information which helped chairpersons arrive at these behaviors, satisfactions and dissatisfactions of chairs with their role, and advice chairpersons would give to new chairs.

\section{Method}

\section{Participants}

Thirty male academic department chairpersons from ten North Central Region Land-Grant Colleges of Agriculture participated in this study. College of Agriculture deans and chairpersons from each of the 10 institutions identified three chairs who had excelled at assisting faculty professionally. Chairpersons whose names appeared most often on the lists were selected for telephone interviewing. Deans and chairs at the ten participating colleges identified sixty-one chairpersons. The number identified at each college ranged from four to ten. Of the thirty chairpersons selected for interviewing, twenty-three were identified by both deans and chairpersons. The remaining seven were identified only by chairs.

\section{Instrument}

Some explanation regarding the structure of the telephone interview is warranted at this point. The two principal styles of interviews are the structured or standardized interview and the unstructured or nonstandardized interview. The structured interview may be sub-divided into "scheduled" and "nonscheduled" interviews. In the scheduled structured interview, the interviewer reads the questions exactly as they are worded and in the order presented in the interview schedule. In the nonscheduled structured interview, the interviewer is afforded choices as to order and wording of quesitons (Assael \& Eastback, 1966; Janofsky, 1971; Kegeles, 1969). A nonscheduled structured interview schedule was developed for this study. The validity and reliability of the interview schedule were tested in a pilot study using six chairpersons, three from one midwestern university and three from one eastern university. 
The interview schedule consisted of 20 questions in 6 sections. Questions in the first section asked for background information. The second section sought behaviors used by the chairs to assist faculty professionally. Other sections of the instrument consisted of questions about conditions which could influence the way chairs assist faculty, methods used to develop administrative skills, information sources, satisfactions and dissatisfactions with their role as chairpersons, and finally, advice they would give new department heads about assisting faculty professionally.

\section{Procedure}

Data were collected through telephone interviews of the thirty department chairpersons. Prior to the interview, the chairpersons were sent an introductory letter describing the purpose of the project, the topic to be covered, and various issues that would be discussed. In addition, they were told the process by which they were selected, the length of time required for the interview, and when to expect the interviewer's call.

The specific method of data analysis for this study was suggested by qualitative methods of interview interpretation (Guba \& Lincoln, 1981; Wolf, 1979) and included: (1) tape recording and transcribing each interview; (2) sorting the interviews for issues, concerns, and factual information; (3) designating the coding unit as the entire interview due to the overlap of responses offered to questions; (4) formulating response categories for content analysis of the interviews; (5) testing the coding instrument for intercoder reliability; and (6) presenting the interview responses as they related to each research question.

\section{Results}

\section{Preliminary Information about Chairpersons}

Chairpersons selected for interviewing headed departments ranging in size from 11 to 69 members with a mean of 30 members. The chairs had served from two to 26 years. Forty-three percent reported prior administrative experience, most commonly serving as department head, program head, or research project director. Thirty percent of the department heads had gained administrative experience in a field other than education. 


\section{Job Satisfaction}

In spite of various frustrations associated with the role of academic department head, e.g., ambiguity of the position, inability to motivate faculty, proliferation of paperwork, and fear of becoming professionally obsolete, chairs were generally satisfied in their role as first-line administrators. Over 75 percent of the department heads cited "accomplishments of faculty" as a major source of satisfaction. "Hiring outstanding faculty," "building a department of national reputation," and "the turnaround of troubled faculty" were also viewed as major job satisfiers providing most chairs sufficient motivation to continue in their role.

\section{Reported Preparation for Chair Role}

Besides observing and interacting with department heads, chairpersons reported using various methods and sources of training and development for their role in assisting the growth and development of faculty: (1) journals, books, and newsletters; (2) workshops, courses, and conferences; (3) on the job training; and (4) trial and error. All chairpersons recognized the need for training. Several, however, complained of too little time for formal development activities.

\section{Conditions Influencing Chairperson Behaviors}

One factor that was cited by most chairs as influencing the way in which they assist faculty was the declining resource base. One department head commented that "money has not been there to bring in the young faculty that we need for our vitality as a department." Additionally, diminishing resources were viewed as challenging the authority of the department head as exemplified by the comment, "in times of contracting resources, the decision- making and the activity of those in the central administration becomes greater." Finally, several chairs concluded that the declining resource base had forced them to assume a more active role in fund raising just to keep their departments and faculty competitive.

\section{Behaviors and Practices Used for Faculty Development}

Three questions provided the framework for the organization of the behaviors and practices chairpersons use to enhance faculty growth and development. First, participants were asked to focus on one faculty member who had grown professionally over the last few years and then to identify how they had assisted this faculty member. Second, the department heads were asked to describe behaviors used with the whole department. 
Finally, the chairs were asked what advice they would give a new department head on how to assist faculty professionally.

An emerging pattern of behavior was identified commencing with the establishment of the appropriate departmental climate: a "supportive, open environment" marked by "honesty and openness" on the part of the department chairperson. The pattern of ongoing behaviors identifed by chairs is one that supports the "movers," reduces the number and magnitude of faculty problems, and fosters early detection of problems that do occur. Respondents offered numerous other recommendations which were sorted into the following six categories (Table 1): recruitment, com-

\section{TABLE 1}

FRAMEWORK BEHAVIORS

\begin{tabular}{ll}
\hline Recruitment & - Hire faculty with excellent skills \\
\hline Communication & - Establish open door policy \\
& - Interact frequently, expecially \\
& - Discuss problems \\
& - Manage by walking around, visit offices and labs \\
& often \\
- Demonstrate a personal interest in faculty \\
research and other actvities \\
- Inform faculty of important administrative issues \\
- Schedule regular planning meetings or retreats
\end{tabular}

Goals Identification
- Develop and communicate reasonable expectations

- Prepare departmental goals with faculty

- Encourage faculty to identify short- and longterm goals

- Help faculty to identify area of expertise

- Counsel, encourage faculty to take training courses, etc.

- Treat faculty as individuals

Support
- Encourage creativity, establish necessary environment

- Encourage faculty participation in campus activities and committees

- Encourage faculty interaction with appropriate peer groups at local, regional, and national level

- Help identify funding sources for faculty

- Assist faculty in grant proposal preparation

- Expect faculty to obtain grant funds

- Provide support for research program 
Table 1, continued.

\begin{tabular}{ll}
\hline FRANE & BEHAVIORS \\
\hline Support (cont.) & - Encourage international opportunities and \\
& expect participation \\
- Support travel to professional meetings \\
- Encourage and expect participation in professional \\
societies \\
- Encourage sabbaticals and faculty development \\
leaves \\
- Stress team concept with faculty \\
- Appoint a mentor for new faculty \\
- Guard faculty time, eliminate trivia \\
- Show confidence in faculty by accepting advice \\
and recommendations \\
- Take faculty from "where they are" versus \\
"remolding" \\
- Advocate for faculty accomplishments, needs, and \\
concerns
\end{tabular}

Evaluation/ Intervention
- Conduct regorous and comprehensive annual evaluations

- Provide continuous feedback to faculty on their performance

- Use peers to review faculty performance

- Conduct exit interview with students on faculty performance

- Use positive reinforcement

- Set timetable for faculty to accomplish goals

- Use shifts in work assignments to challenge faculty

- Change appointment or counsel faculty out of appointment

- Adjust base salary for inequities

- Use salary to reward and motivate

- Give zero salary increases for unproductive faculty

Recognition
- Compliment faculty, write letters of appreciation to faculty with copy to administrators

- Promote early

- Appoint to "select" committees

- Nominate for awards

- Publicize faculty achievement to university, state, and nation

- Reward teaching, research, and extension on an equal basis 
munication, identification of goals, support, evaluation, and recognition. A discussion of each of these behaviors follows.

Recruitment. Recruitment was viewed by chairpersons as a major deterrent to faculty problems, an opportunity to establish new directions in the department, and a chance to bolster faculty morale. One department head commented:

The first thing is, of course, hiring the right people. To me that's a high priority of the job. Because people make the department and if you don't hire the best people you're not going to have the best department.

Eighty-six percent of the respondents indicated that they had hired faculty during their administrative tenure and emphasized the importance of recruiting "top personnel."

Communication. In addition to "hiring the best," "getting to know your faculty" was cited by the thirty department heads in this study as fundamental in assisting the growth and development of faculty. Chairs are proactive in this two-way communication process. Several specific behaviors were identified as being particularly important when communicating with faculty. A thorough orientation process for new faculty can set the stage for further communication between faculty and chairs. While formal communication methods such as faculty meetings, newsletters, memos, and retreats are useful ways to regularly communicate with faculty, an open door policy which permits informal but frequent interaction is also very useful. Many times an incipient crisis can be stopped before it can cause a major problem by the use of any or all of the above behaviors. Of equal importance is the annual evaluation at the end of each year. This evaluation can be particularly meaningful if there is input by both the chairperson doing the evaluating and the staff person being evaluated.

Frequent communication between department head and faculty was viewed as critical to the growth and development of faculty and was facilitated by the chairpersons.

Identification of Goals. Department heads considered goal identification as another important development tool. Helping faculty identify goals, assess opportunities, and set departmental direction was cited by respondents as a major responsibility of department heads and critical to the professional development of faculty. The job description was viewed as integral in this goal identification process. One department head commented:

The best thing you can do for anybody in any job is to define the job description completely the duties, the expectations, and the methods that you're going to use to evaluate that person's performance. If you don't do that I think anything else that you do is pretty much cosmetic. 
Eighty-four percent of the chairs indicated that they give new faculty more individual attention due, in part, to the rigorous promotion and tenure evaluation. Department heads met with new faculty as often as needed to assist in goal assessment prior to the promotion and tenure decision. For established faculty, goal assessment generally occurred during the annual evaluation.

To help faculty detemine job directions, chairs first identified their own expectations and those of the institution. Chairs then encouraged faculty to define their areas of expertise, to indicate how they felt they could best contribute to the department, and to specify how they wanted to make their mark.

Chairpersons helped faculty identify their strengths and weaknesses and worked with them to promote the strengths and eliminate the weaknesses. By identifying the specific forms of development (e.g., toastmasters, campus instructional improvement opportunities, departmental mentoring), chairpersons provided faculty the opportunity for professional growth.

Support. Chairs viewed providing frequent encouragement and support as essential to keeping faculty vital and productive members of the department. Numerous approaches were cited by the chairpersons interviewed as effective means of enhancing faculty morale and performance. Foremost among these were providing adequate facilities, equipment, technicians, and graduate students. Demonstrating confidence in faculty and encouraging participation both within the department and at the college and university level were considered important for growth of both faculty and the department. Although participation in various departmental, college, and university activities was encouraged, chairpersons interviewed felt all faculty should be cautioned against over commitment to committee work. They also felt that committee assignments for new faculty should be limited.

Additional forms of assistance for new faculty included providing released time, encouraging and assisting participation in professional societies, assisting in grant writing and editing, and helping new faculty define research directions. Most department heads felt that assisting new faculty was extremely important, as evidenced by the following comment:

In my view, they are the future of the department, and I feel that I can have a greater impact by putting the emphasis on the young people that are going to be the future. If a choice has to be made, I bank on new faculty.

When dealing with the older, unproductive, faculty member, some respondents indicated they encourage them to consider early retirement. 
A few of the participants in the study counseled "stuck" faculty out of the academic environment. One department head commented:

There comes a time when some faculty clearly know that their career is not going well. They know they're frustrated with research, and their teaching is not that good. I have actually worked with two of our faculty very recently to get them jobs outside the university. I usually try to work hard to get people out of the system as well as to improve them.

Additionally, the department chairs studied supported all faculty by removing obstacles and shouldering added responsibilities. One department head commented:

I've assembled one of the best groups of scientists in the country....They can more productively spend their time doing science, and I can more productively spend my time helping them do it....That means keeping a lot of paper work off their desks.

Some department heads in the study indicated they support faculty by serving as mentors to their assistant professors or by appointing a senior faculty member to serve as a role model. Others encourage interactions with senior faculty on an informal basis.

Generally speaking, these department heads supported sabbaticals and research and development leaves for their faculty, particularly for their mid-career and senior faculty. In addition to supporting participation in sabbaticals and other leave programs, the chairpersons cited altering faculty appointments and helping the mid-career or senior faculty member, whose productivity has declined, focus on a new interest.

Several department heads indicated they promote change, whenever feasible, to encourage faculty vitality and productivity. The chairs in the study often support faculty by anticipating potential problems and initiaing change.

For the more vital and productive faculty member, "getting out of the way" was voiced by several department chairs as the best assistance. One department head commented:

My basic philosophy...is to get out of the way and let them develop. Oftentimes that's more helpful than becoming actively involved.

All chairs viewed themselves as strong advocates of their faculty and of their department. Several department heads stated that they supported faculty by communicating frequently with the appropriate dean concerning their departmental and individual accomplishments and, simultaneously, determined the "mood" of the administration in matters relating to the department. One department head illustrated the importance of communicating department accomplishments to higher ad- 
ministration when he observed that "an informed dean is a supportive dean."

Evaluation. While chairs advocate frequent or continuous feedback to assist faculty professionally, a rigorous and comprehensive annual evaluation process was considered essential for the growth and development of faculty. Many department heads required their faculty to complete an evaluation form stating their activities for the year. They were also asked to list specific goals for the coming year for which they would then be held accountable.

Whitman and Weiss suggest that “...if there exists one conventional wisdom in the field of faculty evaluation it is that using multiple data sources is desirable" (1982, p. 2). Several chairs "distributed the burden of faculty evaluation" through the use of student evaluation for classroom instructors, peer evaluation or review, self evaluation, and exit interviews with graduating seniors.

Department heads identify and address problems throughout the year but often use the formal evaluation process to tackle major issues relating to faculty productivity. Most chairpersons in this study indicated that they schedule a formal meeting with each faculty member to discuss goals and accomplishments, strengths and weaknesses, specific problems and suggested remediation. Thus, the annual conference was often the springboard for initiating significant changes in faculty activity.

Merit salary decisions were closely tied to the evaluation process by department chairs. Most agreed that withholding salary increases for faculty who don't achieve rarely of itself promotes productivity. Several, however, use this practice. One department head suggested that "...it may not be effective, but it frees up additional funds for productive faculty."

Recognition. Finally, recognizing and rewarding faculty was viewed as a deterrent to faculty problems and a reinforcement for faculty productivity. Although strongly tied to the annual evaluation process, department heads reinforce faculty productivity throughout the year. One department head commented:

If I have a faculty member who is extremely productive...I don't ignore the fact that they are doing a superior job except once a year. Pat them on the back. Publicly praise them. I think we have to encourage even those who are doing very, very well to continue to do so.

Forms of recognition used by the chairs were early promotion, salary increases, additional funding, appointment to "select" committees, and nomination for awards. 


\section{Implications and Recommendations}

The implications of the findings combined with the limitations of the study suggest a need for further research in several areas. These needs relate primarily to the training and support of academic department chairpersons and include implications for institutional policy and practice.

The sample in this study was restricted to chairs from ten of the twelve North Central Region Land-Grant Colleges of Agriculture and may not be representative of all department chairpersons. Thus, research could be expanded to include chairpersons from other land-grant and nonlandgrant institutions, both public and private. In addition, the study was limited to the identification of behaviors used by chairpersons to assist faculty professionally. The research could also be expanded to include faculty perceptions of helpful chair behaviors.

Despite various frustrations associated with the role of academic department chair, most participants in this study gained sufficient personal satisfaction to continue in the role of chairperson. Some, however, were anticipating a return to faculty ranks. Research focusing on the special needs of chairs as they return to the ranks of faculty is also warranted.

While much has been accomplished in meeting the evolving development needs of faculty, attention to the state of the professoriate is especially critical today as environmental conditions in higher education continue to deteriorate (Schuster \& Brown, 1985). Most of the chairpersons in this study had scant knowledge of the adult and career development literature. Both chairs and faculty would be advised to become more attuned to developmental literature and to methods of enhancing the growth and development of mid-career and senior faculty. Future research should explore ways in which chairpersons could effectively identify the unique needs of these faculty and assist them in developing or redirecting their talents so that they can continue to be vital, productive members of the department.

Furthermore, the results of this study suggest that chairpersons' effectiveness as faculty developers could be enhanced by stronger institutional support. In this regard, deans and other administrators in Colleges of Agriculture can assist chairpersons in their efforts to enhance the professional development of faculty. This assistance can be accomplished in several ways. First, institutions should select academic department heads based as much on their management qualifications as on their reputations as scholars. To help determine the prospective department head's management orientation, search committees should develop a series of questions to be used in the interview process to determine the candidate's approach to human resource management. In addition, the 
job announcement should reflect the value placed upon human resource management skills by the institution.

Next, the development of pre-service and in-service training directed toward faculty development and other issues confronting academic department chairs is warranted. One proven training ground is the North Central Region New Administrator's Workshop. Support for this or other similar activities is recommended. New chairperson orientation focusing on human resource management and involving deans, vice chancellors, experienced department heads, and administrative staff development experts is also suggested. Deans would be advised to cover university and college policies and procedures as part of this orientation process.

Finally, chairpersons should be evaluated for their efforts to successfully foster the professional development of faculty. Recognition of these efforts would demonstrate to both faculty and chairpersons the value that the institution places on faculty members and on their professional growth and development.

\section{Bibliography}

Assael, H. \& Eastback, J. O. (1966). Better telephone surveys through centralized interviewing. Journal of Advertising Research, 61, 2-7.

Bennett, J. B. (1983). Managing the academic department: Cases and notes (American Council on Education). New York: Macmillan.

Boice, R. (1985). Differences in arranging faculty development through deans and chairs. Research in Higher Education, 23(3), 245-255.

Bragg, A. K. (1980). The relationship between the role definition and socialization of academic department heads. Unpublished doctoral dissertation, Penn State University.

Bragg, A.K. (1981). The socialization of academic department heads: Past patterns and future possibilities. Paper presented at the annual meeting of the Association for the Study of Higher Education.

Dressel, P. L. (1981). Administrative leadership. San Francisco: JosseyBass.

Guba, G. E. \& Lincoln, Y.S. (1981). Effective evaluation. San Francisco: Jossey Bass.

Janofsky, I. (1971). Affective self-disclosure in telephone versus face-toface interview. Joumal of Humanistic Psychology, 11, 93-103. 
Kegeles, S. S. (1969). Interviewing a national sample by longdistance telephone. Public Opinion Quarterly, 33, 412-19.

Knight, W. H. \& Holen, M. C. (1985). Leadership and the perceived effectiveness of department chairpersons. Journal of Higher Education, $56,677-690$.

McLaughlin, G.W., Montgomery, J.R. \& Malpass, L.F. (1975). Selected characteristics, roles, goals, and satisfactions of department chairmen in state and land-grant institutions. Research in Higher Education, 3, 243-259.

Smart, J. C. \& Elton, C. F. (1976). Administrative roles of department chairmen. New Directions for Institutional Research, 10, 39-60.

Tucker, A. (1984). Chairing the academic department. New York: Macmillan.

Wheeler, D.W., Creswell, J.W., Mitchell, M. \& Seagren, A. (1986). Academic departmient chairpersons: Enhancing faculty growth and departmental vitality. Paper presented at the American Educational Research Association Meeting. San Francisco.

Whitman, N., \& Weiss, E. (1982). Faculty evaluation: The use of explicit criteria for promotion, retention, and tenure. Washington, D.C.: American Association for Higher Education.

Wolf, R.L. (1979). Strategies for conducting naturalistic evaluation in socioeducational settings: The naturalistic interview. Occasional Paper Series. Evaluation Center, Western Michigan University. 